\title{
A hybrid approach to stabilization and repair of obstructed total anomalous pulmonary venous connection in a critically ill newborn infant
}

\author{
Jeffrey Meadows, MD, a,c Audrey C. Marshall, MD, ${ }^{a, c}$ James E. Lock, MD, ${ }^{\text {a,c }}$ Mark Scheurer, MD, ${ }^{a, c}$ \\ Peter C. Laussen, MD, ${ }^{a, c}$ and Emile A. Bacha, MD, ${ }^{b, d}$ Boston, Mass
}

\begin{abstract}
Clinical Summary
A $3.9-\mathrm{kg}$ male child was born at full term following an unremarkable prenatal course. Although initially vigorous he quickly developed respiratory distress and was brought to the neonatal intensive care unit where, upon arrival, he developed profound hypoxemia and respiratory failure. He was intubated and placed on conventional mechanical ventilation. A chest radiograph was interpreted as mild cardiomegaly with diffuse hyaline membrane disease. Umbilical arterial and venous catheters (UVC) were placed and his clinical status rapidly deteriorated. Due to refractory hypoxemia, administration of high-frequency ventilation and nitric oxide was attempted without clinical response. Metabolic acidosis and hypotension ensued and high-dose dopamine and prostaglandin were initiated. An echocardiogram was obtained and demonstrated severe biventricular dysfunction. The left atrium appeared small and the pulmonary veins were not visualized. The patient was transferred to this hospital for further evaluation and care.

Upon arrival to this institution the infant was profoundly hypoxemic (peripheral saturation $44 \%$ ), acidotic, and hemodynamically labile, with evidence of early end-organ dysfunction. He was immediately cannulated for veno-arterial extracorporeal membrane oxygenation (ECMO) from the right neck. Repeat echocardiography after stabilization on ECMO failed to demonstrate the pulmonary veins and he was brought to the cardiac catheterization laboratory for anatomic assessment.
\end{abstract}

At cardiac catheterization arterial and venous access was obtained from the right femoral vessels. Hemodynamic evaluation revealed systemic pulmonary artery (PA) pressures despite full ECMO support and evidence of good left ventricular contractility. Angiography demonstrated total anomalous pulmonary venous connection, with near complete infradiaphragmatic drainage (Figure 1 , a). The majority of pulmonary venous return occurred through a single large descending vein that terminated in a venous confluence within the liver before draining to the inferior vena

From the Departments of Cardiology and Cardiac Surgery, 'The Children's Hospital Boston, Boston, Massachusetts, and Departments of Pediatrics ${ }^{\mathrm{c}}$ and Surgery, ${ }^{\mathrm{d}}$ Harvard Medical School, Boston, Mass.

Received for publication Aug 4, 2005; revisions received Nov 14, 2005; accepted for publication Nov 16, 2005

Address for reprints: Emile Bacha, MD, Associate Professor of Surgery, Harvard Medical School, Senior Associate, Department of Cardiac Surgery, Children's Hospital Boston, 300 Longwood Ave. Bader 273, Boston, MA 02115 (E-mail: emile.bacha@cardio.chboston.org).

J Thorac Cardiovasc Surg 2006;131:e1-2

$0022-5223 / \$ 32.00$

Copyright () 2006 by The American Association for Thoracic Surgery

doi:10.1016/j.jtcvs.2005.12.009 cava via the ductus venosus. The previously placed UVC had entered the pulmonary venous confluence and descending vein and was obstructing pulmonary venous return. The UVC was exchanged over a wire for a standard sheath and PA pressures decreased slightly. Further evaluation revealed that the descending vein was obstructed at the crux of the diaphragm and the ductus venosus was small, compounding the obstruction (Figure 1, b). Premounted stents were placed across both the descending vein and ductus venosus and greatly improved pulmonary venous return (Figure 1, c).

Over the course of the next several days the patient's hemodynamic status stabilized and there was return of end-organ function. Diuresis was obtained and ionotropic support was weaned. He was decannulated from ECMO support on his 8th day of life, 5 days after his catheterization. He was taken to the operative suite where he underwent primary sutureless repair of his total anomalous pulmonary venous connection (TAPVC) and ligation of a small ascending vertical vein. His postoperative course was uncomplicated. He returned to the catheterization laboratory prior to discharge for closure of the stent within the ductus venosus, an effective portal-caval shunt, but this was found occluded. He was discharged on his 43rd day of life in excellent condition. Five months following his surgical repair the patient is feeding and growing. Echocardiography demonstrates unobstructed pulmonary venous drainage and normal right ventricular pressures.

\section{Discussion}

Total anomalous pulmonary vascular return is an anatomically heterogenous entity. The anomaly frequently is categorized as either supra- or infradiaphragmatic, with pulmonary venous obstruction being more common in the latter group. ${ }^{1}$ Histologic examination of the pulmonary venous pathway in patients with infradiaphragmatic TAPVC suggests that obstruction may result from either external compression or by intrinsic vessel stenosis. $^{2}$ Obstructed TAPVC is one the classic surgical emergencies. Other than ECMO support, there is no good palliative option besides emergency surgical repair, which often requires deep hypothermic circulatory arrest (DHCA). Thus, neonates are often taken to the operating room with severe pulmonary artery hypertension and pulmonary edema. Disappointing results have been reported with attempts to relieve pulmonary venous obstruction through catheter-based balloon dilation. ${ }^{3}$ To our knowledge, stenting of the anomalous venous pathway has not been reported. In the case presented, ECMO was performed as a lifesaving maneuver prior to establishing the diagnosis. Stenting of the vertical vein and ductus venosus resulted in sufficient relief of pulmonary venous obstruction to permit clinical stabilization and decannulation from ECMO support in preparation for surgical correction. 


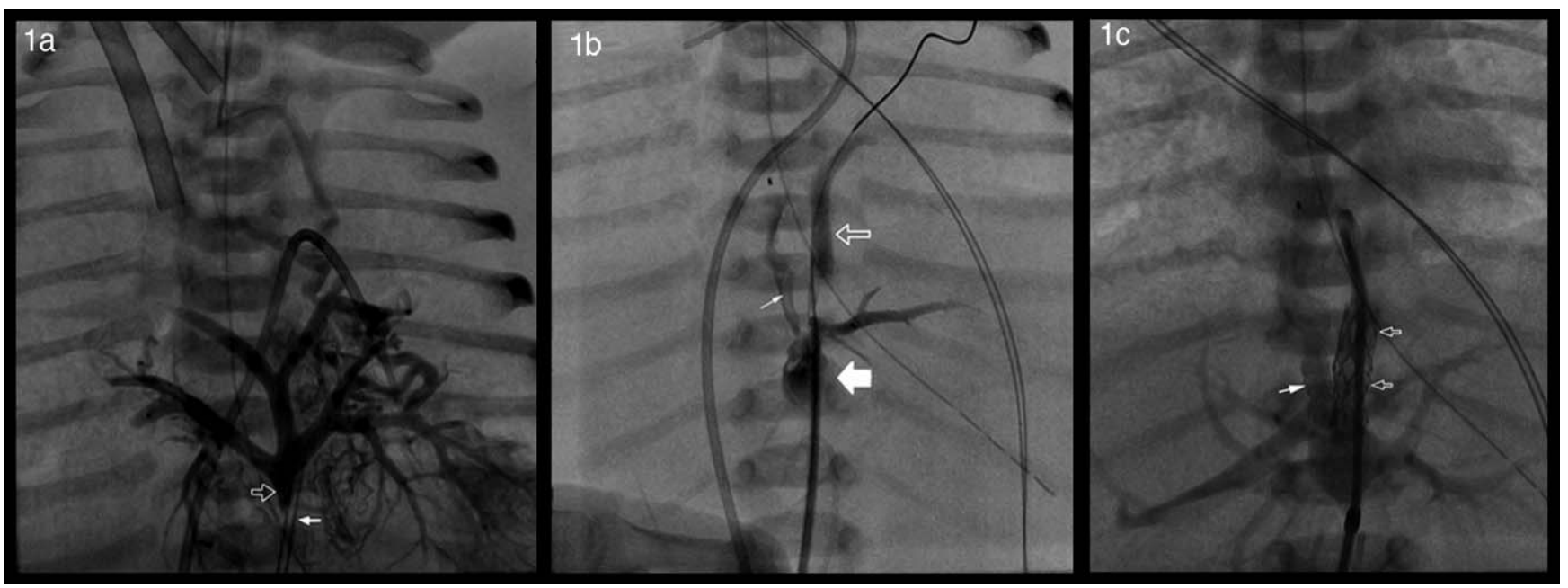

Figure 1. Angiography at cardiac catheterization demonstrates TAPVC. The majority of pulmonary venous return joins a descending vain (open arrows, a and b), which terminates in a large pulmonary venous confluence within the liver (broad arrow, b) before returning to the heart via the ductus venosus (small solid arrow, b). The umbilical venous catheter (solid arrow, a) is seen to traverse the pulmonary venous confluence, terminating within the descending vein. Two stents are placed within the descending vein (open arrows, c). An additional stent is placed in the ductus venosus (solid arrow, c), allowing improved pulmonary venous return to the right atrium.

At the time of repair, the child had recovered end-organ function. DHCA was not used. Because the venous confluence was very poorly developed (Fig. 1, a), a primary sutureless technique was utilized. ${ }^{4,5}$ This has been described as a primary approach for unfavorable anatomy. ${ }^{4,5}$ The present case illustrates that neonates can undergo stenting of the obstructed venous pathway as a temporary measure to allow end-organ recovery and semielective repair under more favorable circumstances.

\section{References}

1. Kirshbom PM, Myung RJ, Gaynor JW, Ittenbach RF, Paridon SM, DeCampli WM, et al. Preoperative pulmonary venous obstruction af- fects long-term outcome for survivors of total anomalous pulmonary venous connection repair. Ann Thorac Surg. 2002;74:1616-20.

2. Lucas RV Jr, Lock JE, Tandon R, Edwards JE. Gross and histologic anatomy of total anomalous pulmonary venous connections. Am J Cardiol. 1988;62:292-300.

3. Lock JE, Bass JL, Castaneda-Zuniga W, Fuhrman BP, Rashkind WJ, Lucas RV Jr. Dilation angioplasty of congenital or operative narrowings of venous channels. Circulation. 1984;70:457-64.

4. Lacour-Gayet F, Rey C, Planche C. [Pulmonary vein stenosis. Description of a sutureless surgical procedure using the pericardium in situ]. Arch Mal Coeur Vaiss. 1996;89:633-6.

5. Yun TJ, Coles JG, Konstantinov IE, Al-Radi OO, Wald RM, Guerra $\mathrm{V}$, et al. Conventional and sutureless techniques for management of the pulmonary veins: evolution of indications from postrepair pulmonary vein stenosis to primary pulmonary vein anomalies. $J$ Thorac Cardiovasc Surg. 2005;129:167-74. 